Revista Española de Antropología Americana ISSN: 0556-6533

http://dx.doi.org/10.5209/reaa.70366

\title{
Un proyecto audiovisual de etnografía colaborativa en construcción: la serie documental La comunicación indígena
}

\author{
Beatriz Pérez Galán ${ }^{1}$ y Yolanda Prieto Ramos ${ }^{2}$
}

Recibido: 2 de julio de 2020 / Aceptado: 1 de septiembre de 2020

Resumen. En esta contribución se describe el proceso de colaboración etnográfica seguido en la serie documental La comunicación indígena. Un derecho en construcción. Realizada bajo la dirección técnica del Centro de Medios Audiovisuales (CEMAV) de la Universidad Nacional de Educación a Distancia (UNED) en el marco del proyecto de investigación "Medios Indígenas". Esta serie contó con la participación de académicos, antropólogos, periodistas y comunicadores indígenas y no indígenas de más de una docena de colectivos y medios de comunicación procedentes de América Latina y del Estado español. Partiendo del reconocimiento a los actores indígenas reiteradamente invisibilizados en los procesos de investigación tradicionales, reflexionamos sobre el lugar de enunciación de los participantes en este proyecto, la audiencia a la que nos dirigimos, y el proceso de selección de imágenes y narraciones, entre otros elementos de un ejercicio experimental de etnografía colaborativa en el ámbito de la comunicación indígena en América Latina.

Palabras clave: metodologías participativas; etnografía colaborativa; comunicación indígena; serie documental.

\section{[en] A Collaborative Ethnography Audiovisual Project under Construction: The Documentary Series Indigenous Communication}

Abstract. This contribution describes the ethnographic collaboration's process in the TV documentary series The Indigenous communication. A right under construction. Produced by The Audiovisual Media's Center (CEMAV-UNED) and within the framework of the Indigenous Media project, this TV serial has counted with the participation of academics, anthropologists and journalists and indigenous and non-indigenous social communicators from more than a dozen of Latin American and Spanish communication's organizations and media. Starting with the recognition of the indigenous actors, repeatedly invisible in the traditional investigation's processes, in this text we reflect on the place of participants, the audience we address to, and the selection of images and narratives as means of a collaborative ethnography's experimental exercise in the context of Latin American indigenous communication.

Keywords: participatory methodologies; collaborative ethnograghy; indigenous communication; TV documentary serial.

Sumario. 1. Etnografía y colaboración. 2. La serie, los participantes y la producción de contenidos. 3. De la ventriloquía a la interlocución. La colaboración etnográfica en el ámbito de la comunicación indígena. 4. Conclusiones: repensar la gramática etnográfica. 5. Referencias.

Universidad Nacional de Educación a Distancia (UNED). beatrizp@fsof.uned.es

2 Centro de Medios Audiovisuales (CEMAV), Universidad Nacional de Educación a Distancia (UNED). yprieto@pas.uned.es 
Cómo citar: Pérez Galán, Beatriz y Yolanda Prieto Ramos. 2020. "Un proyecto audiovisual de etnografía colaborativa en construcción: la serie documental La comunicación indígena". Revista Española de Antropología Americana 50: 229-240.

\section{Etnografía y colaboración}

En las últimas décadas se observa un interés creciente en antropología por el uso de metodologías etnográficas colaborativas que plantean la necesidad de superar la "arrogancia académica" (Borda 2009), positivista y neocolonial que a menudo sigue lastrando nuestras investigaciones. En América Latina la investigación-acción lleva desde la década de 1970 proponiendo metodologías participativas que, desde diferentes perspectivas, incorporan los conocimientos de los actores indígenas reiteradamente invisibilizados en los procesos de investigación tradicionales. Concretamente, desde la primera Declaración de Barbados (1971), redactada conjuntamente por indígenas y antropólogos, que denuncia la naturaleza extractiva de las investigaciones realizadas en comunidades indígenas, un buen número de investigadores empiezan a desarrollar nuevas formas de investigación comprometidas con las luchas por la defensa de los derechos de los pueblos indígenas y en colaboración con ellos.

Leyva y Speed (2008) trazan la genealogía de esas contribuciones a partir de los trabajos pioneros de Freire (1973), aplicados al ámbito comunicativo por Kaplún (1998), y de Fals Borda (2009), hasta la eclosión, en las décadas siguientes, de los estudios postcoloniales, feministas y del pensamiento crítico descolonial que asientan definitivamente la apuesta en América Latina por una epistemología alternativa. El común denominador de estas aportaciones heterogéneas parte de cuestionar la idea del monopolio del conocimiento experto del antropólogo, y, en su lugar, apuestan por formas colectivas de producción de saberes-haceres subalternizados (Santos 2006).

En la última década contamos con un número creciente de experiencias de "investigación etnográfica colaborativa" realizadas entre académicos, intelectuales y activistas indígenas (Lassiter 2005; Rappaport 2007, 2018; Leyva y Speed 2008; Álvarez y Dietz 2014). Para Lassiter (2005: 16) esta forma de hacer etnografía pone el acento en una colaboración deliberada y explícita en cada paso del proceso etnográfico, desde la conceptualización del proyecto hasta el trabajo de campo y el proceso de escritura/elaboración del producto final. Así concebida, la especificidad de esta metodología etnográfica reside en primer lugar en el compromiso ético y moral y la colaboración con los sujetos de estudio. En segundo lugar, el sujeto de estudio pasa de ser concebido como mero "informante" que produce datos para nuestras investigaciones a desempeñar el papel de consultor (Lassiter 2005), co-teorizador (Rappaport 2018) y socio epistémico (Leyva y Shanoon 2008). En tercer lugar, el diálogo generado por la investigación aspira a ser recíproco y busca ponerse al servicio del interlocutor en vez de al servicio del etnógrafo y la Disciplina. Como observan Álvarez y Dietz (2014: 3450) en la etnografía colaborativa el énfasis reflexivo recae no solo en el etnógrafo en su calidad de observador (autorreflexividad) sino que transversaliza toda la investigación, desde las relaciones con las personas investigadas, las propias presencias/ausencias del investigador, las técnicas a utilizar y el propio contexto de la investigación. Desde esta perspectiva, cabe subrayar que la etnografía 
colaborativa no niega la existencia de relaciones de poder, conflicto y tensiones entre los participantes habituales en cualquier proceso de investigación. Por el contrario, el sentido que empleamos la colaboración en este texto, apunta más bien a la búsqueda de una etnografía experimental de coinvestigación, de coproducción de datos y coautoría, que simultáneamente sirva para problematizar nuestras formas concretas de hacer investigación con poblaciones indígenas y afroamericanas.

Antropólogos con experiencia en proyectos colaborativos en comunidades indígenas y afroamericanas (Rappaport 2018), argumentan que esta metodología no es recomendable sólo por razones éticas sino por sus resultados frente a otros procedimientos extractivos tradicionales. Entre las razones aducidas destacan las implicaciones que tiene el diferente posicionamiento de los sujetos que forman parte de la investigación colaborativa, a saber: de un lado, los participantes no académicos, en tanto que coproductores de conocimiento, tienden a proveer más y mejor información cuando tienen algo en juego en los resultados; de otro, los académicos comprometidos en la defensa de los derechos de los colectivos con los que trabajan, asumen una "responsabilidad" diferente. Como observa Hale (en Leyva y Speed 2008: 40): "no es lo mismo hablar sólo para colegas y recibir sus críticas sobre un conocimiento cuyo destinatario es en primer lugar la Disciplina, que saber que la contraparte será partícipe y discutirá los resultados de un conocimiento analítico que es también para ellos".

Bajo los parámetros de una antropología de orientación pública y comprometida políticamente (Gimeno y Castaño 2014) que asume un compromiso con las personas que participan en la investigación, en esta contribución reflexionamos sobre algunos de los alcances y limitaciones a las que se enfrenta la etnografía colaborativa, a partir del proceso seguido en la realización de la serie documental La comunicación indígena. Un derecho en construcción (Pérez y Prieto 2019).

\section{La serie, los participantes y la producción de contenidos}

Realizada bajo la producción y la dirección técnica del Centro de Medios Audiovisuales (CEMAV) de la UNED, en el marco del proyecto de investigación Medios Indigenas" (Universidad de Barcelona) ${ }^{3}$, esta serie surge en mayo de 2017 por iniciativa de Beatriz Pérez Galán, profesora de la UNED y una de las antropólogas integrantes de dicho proyecto. En colaboración con Yolanda Prieto, redactora y realizadora de CEMAV, y un equipo de investigadores multidisciplinar formado por 5 personas (antropólogos, comunicadores y activistas por los derechos de los pueblos indígenas) se conforma un primer grupo de trabajo con el objetivo de dar forma al guion del documental ${ }^{4}$. El CEMAV, en tanto que servicio de especialistas que apoya las tareas docentes e investigadoras del profesorado de la UNED, aporta a este proyecto los medios y los profesionales para la producción y la realización técnica de la

Véase: http://mediosindigenas.ub.edu/

4 El equipo estaba conformado por Elisa García Mingo (antropóloga y periodista, Centro Universitario Villanueva), Jesús González Pazos (antropólogo, ONG Mugarik Gabe, País Vasco), Claudia Silva (comunicadora y fotógrafa colombiana), Yolanda Prieto (realizadora, CEMAV) y Beatriz Pérez (antropóloga, UNED). Posteriormente a este equipo se unió Manuel Chaparro (periodista, Universidad de Málaga). 
serie $^{5}$. Mientras, los investigadores del equipo inicial, activamos nuestra red de contactos ${ }^{6}$ con miembros de colectivos y medios de comunicación indígena de Colombia, Bolivia, Perú, México, Guatemala, México, Chile y Argentina, reconocidos por su incidencia a nivel continental, a los que se invita a colaborar en la construcción de este proyecto en los siguientes términos:

“(...) El objetivo de este proyecto documental es divulgar tanto en España como en América Latina qué es la comunicación indígena y cuáles son las aportaciones de los/las comunicadores/as en su apropiación de los medios y la tecnología para la comunicación (...) se trata de un proyecto abierto y colaborativo que aspira a construirse con las miradas cruzadas de aquí y de allá, y ahí creemos que reside su interés. Les invitamos a la participación mediante sugerencias temáticas y el aporte en la producción de contenidos audiovisuales que puedan contribuir a armar esta propuesta como un recurso útil para las organizaciones que reivindican este derecho (...) El fin de este proyecto es la divulgación social y académica, y como tal, no tiene ánimo de lucro" (Beatriz Pérez, junio de 2017).

En efecto, la invitación a la colaboración consistía en abrir el proyecto a la participación mediante la producción de contenidos a partir del guion de la serie, tal como fue inicialmente concebida por nuestro equipo. Este guion se estructuraba en tres capítulos, cada uno de los cuales abordaba un aspecto de la comunicación indígena: antecedentes (1), derecho a la comunicación propia (2), experiencias (3).

Concretamente, solicitamos la grabación audiovisual de una entrevista de unos 15 minutos de duración dividida en 3 secciones en la que reflexionasen sobre: qué es la comunicación indígena, el proceso de conformación de sus colectivos y medios, y los aportes y retos del ejercicio de la comunicación en sus comunidades. Acompañando a la entrevista, les invitamos a enviar imágenes propias u otro material audiovisual que ilustrase su trabajo. Este material, procedente de los colectivos de comunicación indígena de América Latina, se tejería al de las entrevistas grabadas en Madrid y a las imágenes seleccionadas del Fondo Documental de RTVE ${ }^{7}$ para lograr un producto resultado de las "miradas cruzadas de aquí y de allá". La respuesta fue excelente.

A lo largo de los siguientes 4 meses (hasta octubre de 2018) entablamos un diálogo fluido, casi permanente (teniendo en cuenta las diferencias horarias), con nuestras

\footnotetext{
El CEMAV se encarga de la producción de contenidos para programas educativos desde la fundación de la UNED en 1972. Hasta mediados de los 90 la tecnología utilizada era analógica a través de cintas magnetofónicas, videomagnéticas, radio y televisión. Con la incorporación definitiva de Internet y las nuevas tecnologías de la comunicación en la metodología de enseñanza a distancia a finales de los años 90, el CEMAV comienza la producción de contenidos multimedia. La creación de un canal propio (Canal UNED) diversifica su audiencia y consolida su vocación como un espacio de divulgación científica. En la actualidad, los contenidos de Canal UNED a través de YouTube, RTVE son visualizados por casi 30 millones de personas en todo el mundo, con énfasis en los países hispano-hablantes (comunicación personal de A. Mancebo, director técnico del CEMAV).

6 Nuestro conocimiento previo de los comunicadores indígenas participantes en este proyecto proviene en el caso de 3 investigadores del equipo de trabajos de campo etnográfico realizados en el marco de distintos proyectos de investigación. Los otros 2 investigadores son integrantes de entidades de cooperación al desarrollo que financian proyectos de comunicación indígena en América Latina.

7 La colaboración UNED-TVE se establece en virtud de un convenio de colaboración para la transferencia de conocimiento a la sociedad, según el cual TVE cede al CEMAV espacios semanales de 60 minutos en su programación de radio (Radio 3), y de televisión (La 2 y Canal Internacional) y permite asimismo el acceso a su Fondo Documental.
} 
contrapartes de América Latina a través de internet (correo electrónico, Facebook, WhatsApp, Messenger, Skype). Recibimos propuestas sobre el contenido, consultas sobre el formato o la localización de exteriores, al tiempo que nos transmitían sus dificultades técnicas y personales para la grabación y el envío de materiales:

"Estoy preocupada por las cuestiones técnicas relacionadas a la entrevista. No sé si saben pero nosotros somos sólo un colectivo de comunicadores comunitarios, por lo cual no contamos con equipo de alta calidad para trabajar videos. Tengo a la disposición una cámara Sony con imágenes HD y un micrófono Tascam. No sé si es suficiente si hablamos de una producción profesional. Déjeme decir que no será posible porque no cuento con esos medios. Y con respecto a la forma de envío del material, no se si no hay otra manera de enviar. Para empezar no tengo computador personal, de ser así, sería en un computador público" (Marta Calel, Red Tz'ikín. Extracto de correo electrónico recibido el 8 de agosto de 2017).

La precariedad en la que realizan su labor algunos de los colectivos y medios indígenas, por un lado, y, por otro, las exigencias técnicas de TVE respecto a los estándares de calidad de las producciones que emiten, exigieron un esfuerzo adicional y mucha flexibilidad por parte de todos los participantes en este proyecto. Para el CEMAV era la primera vez que uno de sus documentales se nutría de material producido ad hoc por otros medios "alternativos", y enviados desde América Latina haciendo uso de las nuevas tecnologías de la comunicación. Mientras, para nuestras contrapartes indígenas su participación en este proyecto suponía, en algunos casos un reto, al tiempo que una oportunidad y un reconocimiento a su trabajo por parte de una universidad extranjera.

Gracias a la generosidad de todos los colaboradores, los "de aquí" y los "de allá", se consiguió grabar, enviar y recibir el material haciendo uso de formatos y plataformas gratuitas a través de internet (Icloud, Wetransfer, mp3). En total, recibimos 9 entrevistas desde América Latina y los enlaces para el visionado de más de 200 producciones de material audiovisual y radiofónico.

Durante esos meses, de forma paralela al trabajo de documentación y visionado exhaustivo del material, continuamos con la realización de las restantes 10 entrevistas en Madrid contando con los medios técnicos y humanos del CEMAV: 5 de ellas a los componentes del equipo en Madrid, y otras 5 a comunicadores indígenas aprovechado su paso por España.

En conjunto, la producción de contenidos para esta serie fue de 19 entrevistas de duración variable (entre 30 a 40 minutos las realizadas en Madrid, y de 10 a 20 minutos las de América Latina): 11 de ellas a comunicadores y representantes indígenas $^{8}$ que lideran procesos y medios de comunicación propia a nivel continental, 3 entrevistas a expertos en comunicación y activistas no indígenas de América Latina,

8 Diana Jembuel, comunicadora misak (Colombia), Patricia Yallico, documentalista y cineasta kichwa (Ecuador), Marta Calel y Enma Cucul, comunicadoras mayas queqchi (Guatemala), Olimpia H. Palmar y David Hernández comunicadores wayúus (Venezuela/Colombia), Jeannette Paillán, cineasta mapuche (Chile), Julio Quispe, comunicador quechua (Perú), Guillermo Mamani, comunicador aymara (Argentina), Mariano Estrada, comunicador tseltalteco (México), Sandra Cossio, comunicadora quechua, CAIB (Bolivia).

9 Pablo Mora, Mari Flores e Iván Sanjinés (CEFREC, Bolivia), expertos en cine y video indígena y referentes en la lucha por el derecho a la comunicación indígena en Colombia y Bolivia, respectivamente. 
y las restantes 5 a los investigadores del equipo en Madrid.

Con esas voces e imágenes, a modo de retales coproducidos por académicos, antropólogos, comunicadores, activistas, y casi una veintena de colectivos y medios indígenas que se fueron sumando a este proceso ${ }^{10}$ comenzamos la construcción del guion y el montaje de forma paralela. De hecho, y dado que la base para la construcción del guion fue el visionado de todo el material y los diálogos con nuestras contrapartes, el trabajo de guionización más importante fue llevado a cabo, no sobre el papel, sino sobre la misma línea de tiempo del programa de edición premiere. Esta realización en montaje, aunque más laboriosa y exigente en tiempo, respondía mejor a las necesidades de un proyecto abierto a la colaboración de todos los participantes.

La serie, dividida en 3 capítulos de media hora de duración cada uno, se estrenó entre mayo de 2018 y enero de 2019 en La 2 de TVE y simultáneamente en Internet (YouTube, RTVE y Vimeo). Además, está alojada como recurso audiovisual en los sitios web de varias de las organizaciones y medios participantes, así como de otros grupos y agencias de noticias de América Latina y del Estado español.

En la primavera de 2019, a propuesta de varios participantes, se decide retomar el proyecto con el objetivo de mejorar su difusión y hacer más visible el reconocimiento a todas las personas y colectivos que han colaborado en la serie. La realización de un tráiler y el subtitulado al inglés de cada capítulo se plantean como vías para favorecer la difusión en espacios internacionales y a través de las redes. Mientras, para mejorar la visibilidad y el reconocimiento del trabajo realizado por todos nuestros colaboradores, optamos por tres vías, dos de las cuales continúan en proceso: la incorporación de los créditos finales en el tercer capítulo, el pago de derechos de autor a la orquesta indígena por el tema utilizado como la banda sonora de la serie ${ }^{11}$ y, por último, su exhibición en distintos foros de comunicación indígena, festivales y muestras de cine sobre Derechos Humanos, tanto en España como en América Latina $^{12}$. En la actualidad varias de estas tareas están en proceso por lo que el proyecto continúa abierto y en construcción.

En las siguientes páginas incidimos en algunos aspectos concretos de la metodología colaborativa seguida en esta serie, haciendo énfasis en el "para quién" y

10 En total colaboraron en la producción y cesión de contenidos de audio y video para la serie casi una veintena de organizaciones de América Latina: Corporación de Productores Audiovisuales, de Nacionalidades y Pueblos de Ecuador (CORPANP); Agencia de Comunicación Intercultural (SERVINDI); Red de comunicadores indígenas de Perú (REDCIP); Coordinadora Audiovisual Indígena Originaria de Bolivia (CAIB); Centro de Formación y Realización cinematográfica (Bolivia, CEFREC); Bolivia TV, Red de Comunicación wayúu y Escuela de Comunicación wayúu Putchimayana (Colombia-Venezuela); Coordinadora Latinoamericana de Cine y Comunicación de los Pueblos Indígenas (CLACPI); Colectivo Zhigoneshi (Colombia); Radio Colombia Nativa; Nasa Corinto TV (Colombia); Nasa Estereo (Colombia); Red Tz'ikin de realizadores Independientes de Guatemala; Ficwallmapu (Chile); ADKIMVN Cine y Comunicación Mapuche (Chile); Ficmayab (Guatemala); Radio comunitaria Kimché Mapu (Chile); Radio Pío XII (Bolivia); Radio Lachiwana (Bolivia); Radio Pachamama (Perú), Radio Nativa (Bolivia), Revista Jallalla (Argentina) y Fuegos TV (México).

11 El tema escogido "Convocando a la unidad" pertenece a la Orquesta de Instrumentos andinos del resguardo indígena Huellas de Caloto (Cauca, Colombia). La Orquesta está conformada por niños y jóvenes de los resguardos indígenas vecinos que han sobrevivido al conflicto armado e integran desde 2003 la "Escuela Nasa de Arte y Música del Resguardo Huellas", bajo la dirección del profesor Richard Escobar y el impulso de la Fundación Caminos de Identidad.

12 X Muestra de Cine y Video Indígena (Alicante, 2019); X Jornadas de Antropología de la UNED (Madrid, 2019); VII Festival de Cine y Derechos Humanos de Donostia (2019); I Encuentro Internacional de Comunicación Indígena (Cuzco, 2019), y en el 56 Congreso Internacional de Americanistas (Salamanca, 2018). Además, la serie ha sido emitida en la programación de Canal 15 (Costa Rica), Plurinacional TV (Bolivia), y Apak Otavalo TV (Ecuador). 
en el "cómo" y su influencia en el producto final. Es necesario tener en cuenta que la colaboración en el caso de esta serie documental no surge como una demanda o una necesidad de los colectivos indígenas de comunicación participantes, y tampoco figura como tal en nuestra propuesta inicial. Más bien se configura como un modus operandi a medida que avanzamos. Desde esa perspectiva, nos interesan no tanto los puntos de partida como la forma en la que, en el transcurso de la elaboración de los documentales, se modifican las posiciones iniciales y se incorporan otros temas que responden a los intereses y las demandas de nuestras contrapartes en América Latina (Katzer y Samprón 2012).

\section{De la ventriloquia a la interlocución. La colaboración etnográfica en el ámbito de la comunicación indígena}

Como señalamos, el primer guion de la serie fue concebido como una secuencia dividida en tres capítulos en los que narrar, desde nuestra mirada como académicas y antropólogas, la historia del desarrollo de la comunicación indígena y la paralela constitución de los pueblos indígenas como sujetos políticos en su apropiación de los medios y las nuevas tecnologías de la comunicación. Según esta propuesta, los primeros dos capítulos ("Antecedentes históricos" y "Derecho a la comunicación propia", respectivamente) se articulaban a partir de una voz en off que dirigía el hilo argumental y cuya narración era avalada por el relato de los expertos del equipo en Madrid. Esta puesta en escena, habitual en los documentales de Canal UNED, se remataba con las imágenes procedentes del fondo documental de RTVE. Mientras, las entrevistas solicitadas a los comunicadores indígenas "encajaban" idealmente en el capítulo tercero, dedicado a tratar las experiencias de los colectivos y medios indígenas. Pronto nos dimos cuenta de que este planteamiento no era el más adecuado.

La apertura del proyecto a comunicadores y líderes indígenas desde el reconocimiento del lugar que ocupan como sujetos para hablar con autoridad sobre qué es la comunicación propia que llevan décadas construyendo y practicando, nos permitió superar la incongruencia que implica producir conocimiento sobre el derecho a comunicar de otros pueblos sin contar con los comunicadores o, peor aún, hacerlo de forma marginal como si se trataran de meros productores de información.

Concordamos con Rappaport (2007: 346) cuando señala que la colaboración etnográfica precisa de unas condiciones, unos interlocutores y de un compromiso de los participantes para su realización que, en nuestro caso, se cumplían. En primer lugar, el conocimiento previo y la relación de confianza mutua sostenida en el tiempo con la mayoría de nuestras contrapartes indígenas y no indígenas de América Latina a las que invitamos a participar facilitó mucho la comunicación (véase nota 4). En segundo lugar, la posición "privilegiada" de varios de ellos como artífices de procesos de comunicación propia considerados paradigmáticos a nivel internacional y su liderazgo en la defensa de derechos de los pueblos indígenas, nos cuestionaba el esquema de interlocución "ellos-objetos de conocimiento" versus "nosotras-investigadoras expertas". En tercer lugar, el uso extendido de las redes sociales y de las nuevas tecnologías de la comunicación por parte de los comunicadores fue clave para crear y habitar un espacio compartido que posibilitó la interacción y la reflexión sobre la propia naturaleza y los usos indígenas de los medios. Como observa Canals (2000), a diferencia de otros objetos de estudio clásicos de la antropología, la co- 
municación es por definición multisituada y tecnológicamente mediada y, como tal, permite una continuidad entre aquello que se investiga (los medios) y la forma de estudiarlo (la mediación digital).

\subsection{El ajuste de la lente}

El primer visionado de las entrevistas enviadas y la interacción a través de las redes con nuestras contrapartes nos permitió establecer una mínima estructura de narración y un punto de partida que daba prioridad a sus formas de contar(se) y ver(se).

Estos relatos e imágenes situaban una parte esencial del derecho a la comunicación propia en realidades marcadas por la violencia y la creciente criminalización de líderes sociales - muchos indígenas- por la defensa del derecho al territorio y a la vida frente a la implacable extensión de la economía extractiva en todo el continente. La búsqueda de narrativas alternativas frente a los grandes grupos mediáticos y la necesidad de visibilizar esta situación había llevado al surgimiento de medios y procesos de comunicación indígena en cascada desde finales de la década de los años 90 hasta hoy. Desde esa perspectiva, los radiofonistas, comunicadores, documentalistas y cineastas indígenas que se suman a los distintos proyectos de comunicación en toda América Latina, convergen en una búsqueda que tiene que ver no solo con el control de la representación sino, sobre todo, como habitan un lugar de resistencia.

Desde esa perspectiva más amplia e integral la comunicación se va configurando a cada paso que avanzamos como una arena de la práctica política indígena. Un lugar para la acción colectiva y la experimentación cultural (Orobitg 2019), tanto "hacia afuera", a nivel nacional e internacional, en su labor de denuncia y visibilización de la violencia estructural y los procesos de desposesión a nivel simbólico-cultural que sufren. Y, simultáneamente, "hacia adentro", a nivel comunitario-local, mediante el fortalecimiento de las señas de pertenencia colectiva y de la puesta en valor de lo propio (Pérez 2020). La tensión "dentro-fuera" utilizada para contrastar los espacios sociales, culturales y políticos indígenas y no indígenas ${ }^{13}$, es también característica de la retórica de la comunicación indígena que irradia desde el movimiento indígena en Colombia al resto del continente. En nuestro proyecto fue clave para afianzar el hilo conductor y replantear "a quiénes" nos dirigíamos y el "para qué" de este proyecto audiovisual. No se trataba sólo de satisfacer el interés científico por el análisis la comunicación indígena como un objeto de estudio, sino prioritariamente de proveer un recurso práctico con el que contribuir a poner en valor y difundir globalmente haciendo uso de las nuevas tecnologías de la comunicación el trabajo de los comunicadores indígenas en la defensa del territorio y la cultura, y simultáneamente hacia sus comunidades, regiones, pueblos y ciudades, desde la posición privilegiada que otorga la atalaya académica-universitaria, como un valor añadido.

Situadas desde esa perspectiva, más política y comprometida, comenzamos un proceso metodológico de colaboración y re-aprendizaje de la comunicación indígena "desde abajo" y "desde adentro" que repercutió en todas las fases del proyecto.

13 En su descripción del tipo de colaboración etnográfica establecida con líderes indígenas del Cauca (Colombia), Rappaport (2018: 335) señala que el adentro no se agota en lo comunitario-local en oposición al afuera de la sociedad nacional. Lejos de ser una dicotomía rígida y esencialista que simplifica una realidad compleja los dos espacios pueden ser yuxtapuestos dependiendo de las necesidades de identificación y de la coyuntura política. 
No obstante, la propia naturaleza colaborativa, reflexiva y dialógica de todo el proceso metodológico redundó en una superposición de tareas y fases alejada de una secuencia lineal y ordenada, como a menudo se suelen presentar el proceso de construcción del objeto de estudio en etnografía que tratamos a continuación.

\subsection{El making off}

\subsubsection{La documentación audiovisual y la voz en off}

La tarea de documentación para la serie resultó extremadamente laboriosa y compleja y abarcó prácticamente todo el proyecto. La distinta procedencia geográfica y cultural de los participantes indígenas y no indígenas, su ubicación en distintos países, sus diferentes posiciones (de género, generación, clase social y formación), y el envío de material autoproducido mediante archivos digitales a través de las redes, fueron algunos de los factores causantes de esa complejidad. El visionado de más de 200 producciones, de procedencia, temática y duración diversa, y la transcripción de las entrevistas, se orientó no sólo a la selección de los fragmentos idóneos para el discurrir de relato a modo de piezas que encajan en una idea y en una estructura predeterminada, como suele ser habitual. Por el contrario, se puede decir que forjó el relato mismo por cuanto nos permitió aprehender el significado de la comunicación indígena. Interpelando al concepto clásico y lineal de "comunicación", emisor-mensaje-receptor, para hacerlo más poroso, más extenso, más rico en manifestaciones y en enfoques.

Una comunicación enraizada en la experiencia indígena, plenamente conectada con la vida, cuyos contenidos y formas expresivas reflejan sus preocupaciones, pero también sus maneras de resistir. Ya sea el maquillaje ritual u otras formas de expresión artística, el tejido, la radio, el audiovisual y el cine, aparecían de forma recurrente tanto en sus relatos, como en las imágenes enviadas y en las localizaciones escogidas para realizar las entrevistas. También el carácter ancestral y sagrado de la comunicación, que hunde sus raíces en las tradiciones de los pueblos indígenas, para combatir la desinformación de los medios de comunicación de masas sobre sus formas de vida y sus intereses.

El visionado exhaustivo de las producciones fue también esencial para modular el uso que inicialmente le habíamos asignado a la voz en off en la serie que pasó a ser utilizado sólo en el primer capítulo como un recurso expresivo útil para conectar tiempos y lugares distintos y tejer un relato con otras miradas menos académicas. En los capítulos siguientes la voz en off desaparece por completo y la selección de fragmentos de entrevista prioriza los relatos indígenas frente a los académicos. El fin de la ventriloquía.

Esta misma lógica argumental, resultante del proceso reflexivo y colaborativo, marcó también la selección de imágenes. En el primer capítulo, especialmente para ilustrar las secuencias que hacen retrospectiva histórica de la comunicación indígena, nos servimos de materiales de imágenes procedentes del archivo documental de TVE. Mientras, los siguientes dos capítulos se nutrieron completamente de materiales audiovisuales auto-producidos por grupos y medios indígenas enviados a través de Internet. 


\subsubsection{El guion y el montaje en realización}

Una vez sentadas las bases epistemológicas desde las que construimos el relato, para quién y para qué, éste empezó a seguir su curso, reclamando aquí una secuencia descriptiva, aquí un testimonio, aquí una visión más de conjunto, aquí una conexión con otro aspecto más personal, más social o más político.

Paulatinamente el guion se convierte en un diálogo entre, por un lado, las reflexiones que los comunicadores indígenas expresan en sus entrevistas respaldados por secuencias concretas de sus materiales audiovisuales y, por otro, las aportaciones del equipo de investigadores en Madrid apoyadas en el material del fondo documental de RTVE. Poner en diálogo las reflexiones que los comunicadores/as indígenas, sus materiales audiovisuales, con nuestros planteamientos, nos permitió construir argumentos cada vez más sólidos y compactos para confluir finalmente, en una conversación de muchas voces, más amplia, diversa y recíproca sobre qué es la comunicación indígena.

\subsubsection{La postproducción. El globo terráqueo y la tarea de nombrar}

Como un recurso expresivo que nos permite situar geográficamente a los comunicadores y a los expertos, de aquí y de allí, en sus territorios, y de homogeneizar visualmente las distintas entrevistas, con una factura técnica muy desigual, generamos una composición en $3 \mathrm{D}$ de un globo terráqueo en movimiento que va ubicando en el mapa las diferentes áreas indígenas, sobre la que vamos abriendo ventanas, a modo de presentación, con la imagen de cada participante.

Se trata de un recurso visual que da una visión comparativa de la comunicación indígena a nivel continental y que sitúa a los diferentes expertos y colectivos de comunicación geográficamente, pero no solo. También los sitúa políticamente, transmitiendo, en un golpe visual, una perspectiva política que tiene que ver con las demandas territoriales de los grupos indígenas frente a las demarcaciones políticas nacionales.

Por último, finalizado el montaje de los capítulos nos dimos a la tarea de buscar y consensuar un título "adecuado" para cada uno de ellos, lo que abrió ricas discusiones entre los participantes que reflejaban nuestros distintos lugares de enunciación y objetivos diversos.

Como metáfora del proceso de apropiación indígena de la comunicación tecnológicamente mediada desde voces y miradas propias titulamos el primer capítulo La conquista de la propia mirada. En él se aborda la convergencia de coyunturas históricas, formas de expresión y de actores sociales de naturaleza muy diversa que favorecen el surgimiento de esa comunicación.

Por su parte, en el capítulo 2, Voces propias. Tejiendo la palabra, escogemos la metáfora del tejido frecuente en la retórica de la comunicación indígena ${ }^{14}$. Esta imagen de "urdimbre de hilos" nos permite entrar de lleno en los procesos y medios que surgen a partir de los años $90 \mathrm{y}$ asumir una de las demandas permanentes de nuestras contrapartes indígenas: situar el foco de análisis en la lucha por el derecho al territorio, la vida y la cultura que desarrollan los comunicadores indígenas a través de los

14 El Tejido ACIN (Asociación de Cabildos Indígenas del Norte del Cauca, Colombia) es uno de los procesos seminales de comunicación indígena en el continente desde donde se generaliza el uso de la metáfora la idea del tejido indígena como convergencia de procesos que reflejan una forma singular de hacer comunicación. 
medios frente a las amenazas de la economía extractiva.

El último capítulo, Voces de Abya Yala, cierra ese círculo de la comunicación indígena como un lugar de resistencia política y cultural desde donde experimentan y construyen su forma de ser y sentirse indígenas. Y desde esa perspectiva, proponemos convertirlo en un homenaje a todos los comunicadores indígenas asesinados o criminalizados por ejercer el derecho a la comunicación propia ${ }^{15}$.

\section{Conclusiones: repensar la gramática etnográfica}

En este texto hemos presentado algunos de los aspectos más relevantes del proceso de construcción polifónica y participativa de la serie documental La Comunicación Indígena. Un derecho en construcción.

La aproximación experimental, casi intuitiva, a los procedimientos de la etnografía colaborativa para el estudio de la comunicación indígena seguida en este proyecto ha sido posible por un conjunto de circunstancias que han favorecido la creación de un diálogo recíproco. A saber: las características del propio objeto de estudio -el estudio de la comunicación mediante las nuevas tecnologías de la comunicación y su uso generalizado entre todos los participantes-, la relación previa de confianza mutua forjada en anteriores experiencias, su propia condición de expertos en comunicación y defensores de los derechos de los pueblos indígenas, y nuestro compromiso con esa defensa y con un tipo de antropología inquieta y comprometida con la situación social y política de los colectivos estudiados, como presupone la naturaleza comprometida de la investigación etnográfica colaborativa.

La apertura del proyecto a la participación de los comunicadores indígenas en la producción de contenidos y sugerencias sobre el guion redundó asimismo en una redefinición de los objetivos de la serie, de la estructura narrativa, y marcó la selección de imágenes y voces, y el uso de algunos de los recursos expresivos empleados (como la voz en off y el globo terráqueo en tres dimensiones), para dar prioridad a sus formas de ver(se) y narrar(se) situadas en un territorio concreto. De ese modo, transitamos de una construcción jerárquica y lineal de la comunicación indígena como un objeto de estudio, hacia la búsqueda de un producto audiovisual realizado colectivamente que contribuyese a la visibilidad "hacia afuera" de la situación de violencia estructural e inequidad que experimentan en todo el continente, y simultáneamente "hacia adentro", como un ejercicio de reconocimiento de la labor que realizan los colectivos y medios indígenas en sus territorios.

Por último, la experiencia del reconocimiento de todos los sujetos participantes en este proyecto, de sus aportes, y de sus lugares de enunciación, nos ha descubierto las potencialidades metodológicas y teóricas de la etnografía colaborativa. Desde ese reconocimiento conseguimos habitar y compartir un espacio común para reflexionar sobre comunicación indígena que permanece vivo y en construcción.

15 https://www.rtve.es/alacarta/videos/uned/uned-indigenas/5184980/. 


\section{Referencias}

Álvarez, Aurora y Günther Dietz. 2014. «Etnografía colaborativa. Coordinadas desde un proyecto en curso (intersaberes)», en Periferias, fronteras y diálogos. Actas del XIII Congreso de Antropología de la FAAEE, pp. 3447-3471. Tarragona: Universitat Rovira i Virgili.

Canals, Roger. 2020. «La web Medios Indígenas: una plataforma para la investigación, la difusión y la comunicación» Proyecto MEDIOS INDÍGENAS. http://mediosindigenas.ub.edu/2020/05/16/la-web-medios-indigenas-una-plataforma-para-la-investigacion-la-difusion-y-la-comunicacion/.

Fals Borda, Orlando. 2009. «La investigación acción en convergencias disciplinarias». Revista PACA 1: 7-21. https://doi.org/10.25054/2027257X.2194.

Freire, Paolo 1973. La pedagogía del oprimido. México: Siglo XXI Editores

Gimeno, Juan Carlos y Ángeles Castaño. 2014. «Antropología y descolonialidad. Desafíos etnográficos y descolonización de las metodologías», en Periferias, fronteras y diálogos. Actas del XIII Congreso de Antropología de la FAAEE, pp. 3433-3446. Tarragona: Universitat Rovira i Virgili.

Katzer, Leticia y Agustín Samprón. 2012. «El trabajo de campo como proceso. La “etnografía colaborativa" como perspectiva analítica». Revista Latinoamericana de Metodología de la Investigación Social 2: 59-70.

Kaplún, Mario. 1998. Una pedagogía de la comunicación. Madrid: La Torre.

Lassiter, Luke. 2005. The Chicago Guide to Collaborative Ethnography. Chicago: Chicago University Press.

Leyva, Xochitl y Shannon Speed. 2008. «Hacia la investigación descolonizada: nuestra experiencia de co-labor», en Gobernar en la diversidad: experiencias indígenas desde América Latina. Hacia la investigación de co-labor, Xochitl Leyva, Araceli Burguete y Shannon Speed, coords., pp. 34-52. Quito: FLACSO.

Orobitg, Gemma. 2019. «La comunicación indígena, una práctica descolonizadora y para impulsar las lenguas indígenas», Proyecto MEDIOS INDÍGENAS. http://mediosindigenas. ub.edu/2019/08/26/2844/

Pérez Galán, Beatriz. 2020. «Comunicamos para la vida. Género y medios de comunicación indígenas en Bolivia Medios Indígenas», en Teorías y experiencias de la comunicación indígena en América Latina, Gemma Orobitg, ed. Madrid: Iberoamericana/Vervuert (en prensa).

Pérez Galán, Beatriz y Yolanda Prieto Ramos. 2019. La comunicación indígena. Un derecho en construcción. Madrid: UNED/Serie documental de tres episodios: 29', 2018-2019. https://vimeo.com/user99091090.

Rappaport, Joanne. 2007. «Más allá de la escritura. La epistemología de la etnografía en colaboración». Revista Colombiana de Antropología 43: 197-229.

—. 2018. «Más allá de la observación participante: la etnografía colaborativa como innovación teórica», en Prácticas otras de conocimiento(s): Entre crisis, entre guerras, Tomo I. Joanne Rappaport et al., coords., pp. 323-352. Buenos Aires: CLACSO.

Santos, Boaventura de S. 2006. Renovar la teoría crítica y reinventar la emancipación social. Buenos Aires: CLACSO. 